\title{
Cholinesterase Activity of Motor
}

\section{End Plate in Human Skeletal Muscle}

\author{
Tatsuji Namba and David Grob \\ From the Department of Medicine, Maimonides Medical Center and State \\ University of New York, Downstate Medical Center, \\ Brooklyn, New York 11219
}

\begin{abstract}
A в S T R A C T The activity and properties of cholinesterase of the motor end plate in human intercostal muscle were studied in the isolated muscle membrane. This preparation was used because cholinesterase activity of the membrane preparation was localized in the motor end plate without contamination of cholinesterase of other muscle components. Under the experimental conditions, cholinesterase in a human end plate hydrolyzed $1.21 \times$ $10^{8}$ molecules of acetylcholine per msec, which is smaller than hydrolysis of $2.69 \times 10^{8}$ by a motor end plate of rat intercostal muscle. Studies with cholinesterase inhibitors and specific substrates indicated that about $90 \%$ of cholinesterase of human motor endplates is acetylcholinesterase, and about $10 \%$ is pseudocholinesterase. The end plate cholinesterase had an optimal $\mathrm{pH}$ of 7.8 and a Michaelis-Menten constant of 4.15 mmoles/liter, and was stable at $4^{\circ} \mathrm{C}$ for at least 4 wk. Motor end plates were estimated to contain only about $2 \%$ of the total cholinesterase activity of human intercostal muscle, compared with about $20 \%$ in rat tibialis anterior muscle. The difference is due to the lower cholinesterase activity of the motor end plate and higher cholinesterase activity of non-end plate components in human muscle than in rat muscle. The isolated muscle membrane provides a useful preparation for the study of the properties of motor end plate in human skeletal muscle.
\end{abstract}

\section{INTRODUCTION}

Cholinesterase plays a cardinal role, together with acetylcholine and acetylcholine receptor. in cholinergic transmission including the neuromuscular transmission. Cholinesterase of the neuromuscular junction may play a role in the pathophysiology of diseases of neuromuscular transmission, and in the action of drugs which affect neuromuscular transmission. However, there has been no quantitative study of cholinesterase activity of the

\footnotetext{
Received for publication 24 October 1969.
}

motor end plate of human skeletal muscle. In a previous communication, the authors reported cholinesterase activity of the motor end plate of rat skeletal muscle, by use of an isolated muscle membrane preparation (1). This preparation was used because cholinesterase activity of the muscle membrane is localized in motor end plates.

In the present study, the activity and properties of cholinesterase of the motor end plate of normal human intercostal muscle were estimated in the isolated muscle membrane. The intercostal muscle was chosen since this muscle is mainly used in microelectrophysiological studies of human motor end plates.

\section{METHODS}

Human intercostal muscle was obtained during postmortem examination performed within $5 \mathrm{hr}$ of death from the fifth to eighth intercostal spaces of patients with no history of neuromuscular disease.

The muscle homogenate was prepared by homogenizing the muscle in a Waring Blendor with $50 \mathrm{~mm} \mathrm{CaCl}_{2}$ and then filtering through 18 mesh plastic net. In order to prepare the muscle membrane fraction, the sarcoplasmic components of the homogenate were dissolved and removed by repeated washing. Details of these methods have been described in a previous communication (1).

Cholinesterase activity was measured by the hydroxamic acid method (2). Incubation was performed at $37^{\circ} \mathrm{C}$ for 30 min in a medium which contained $4 \mathrm{~mm}$ acetylcholine bromide, $100 \mathrm{~mm} \mathrm{NaCl}, 10 \mathrm{mM} \mathrm{MgCl}_{2}$, and $30 \mathrm{~mm}$ sodium phosphate buffer, $\mathrm{pH} 7.5$, unless otherwise indicated. Nitrogen was measured by the micro-Kjeldahl method.

Staining for cholinesterase activity in muscle sections or in the membrane fraction was performed using acetylthiocholine as the substrate (3). To visualize motor end plates of the muscle membrane, an aliquot of membrane suspension was spread on a Millipore filter, type SM (pore size, 5.0 $\pm 1.2 \mu)$. The number of motor end plates was counted under a microscope, and the diameter of motor end plates was measured by an ocular micrometer with graduations of $1.25 \mu$. Statistical analyses were performed as described by Goldstein (4). 

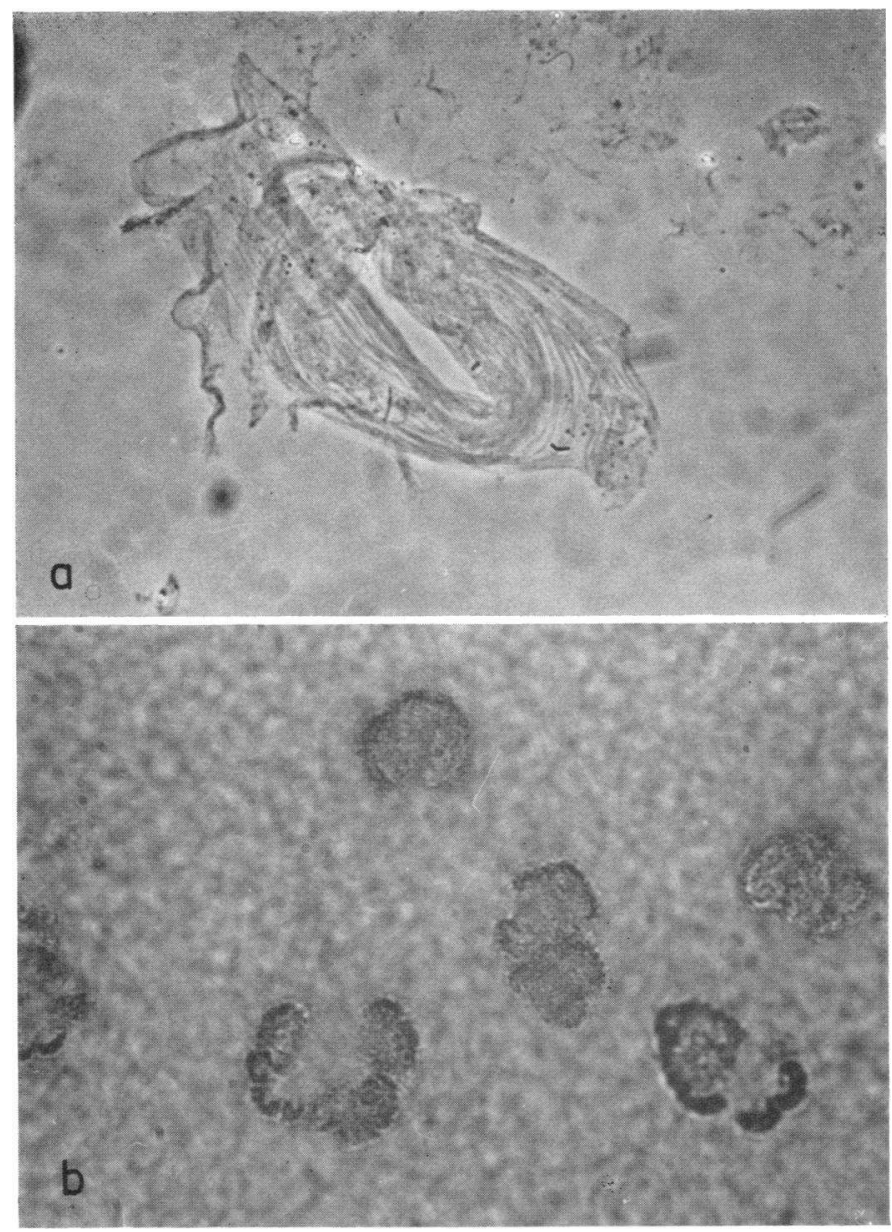

FIGURE 1 Isolated membrane fraction of human intercostal muscle. (a) unstained sample under phase contrast microscopy, $\times 125$, and (b) motor end plates demonstrated by cholinesterase staining. $\times 500$.

\section{RESULTS}

Properties of isolated human muscle membrane. The muscle membrane was recovered as a white, fluffy suspension, which under the phase-contrast microscope consisted of semitransparent or granular membranes of various shapes (Fig. $1 a$ ). The appearance was not altered by storage in suspension at $4^{\circ} \mathrm{C}$ for 6 months. Numerous motor end plates were visualized in the membrane by staining for cholinesterase activity (Fig. $1 b)$. The fine structures of these end plates were similar to structures of end plates demonstrated in muscle sections, including the presence of isolated sole plates. This appearance is in contrast to the continuous network of the sole plates in rat motor end plates (1). The end plates appeared swollen in the membrane stored at $4^{\circ} \mathrm{C}$ for 3 months, and became diffuse cholinesteraseactive spots in the membrane stored for 6 months, prob- ably due either to inactivation or diffusion of the enzyme. Motor end plate was the only structure demonstrated by staining the membrane for cholinesterase.

Cholinesterase activity of human muscle membrane. The cholinesterase activity of human skeletal muscle membrane per unit nitrogen was 3.86 times greater $(P<0.001)$ than the cholinesterase activity of the total muscle homogenate (Table I). This yield was disappointingly low, compared with the 27.1 times greater concentration of activity achieved by isolation of rat muscle membrane. The low yield was due mainly to the high cholinesterase activity of non-end plate components and partly to low cholinesterase activity of motor end plates. Whereas the cholinesterase activity per nitrogen was 4.67 times greater in human muscle homogenate compared with rat muscle homogenate, the cholinesterase activity of human muscle membrane was only $64.5 \%$ of the activity of rat muscle membrane. 
TABLE I

Cholinesterase Activity of Intercostal Muscle

\begin{tabular}{lcccc}
\hline & $\begin{array}{c}\text { Membrane* } \\
\text { (No.) }\end{array}$ & $\begin{array}{c}\text { End plate } \\
\text { (No.) }\end{array}$ & $\begin{array}{c}\text { Homogenate* } \\
\text { (No.) }\end{array}$ & $\begin{array}{c}\text { Membrane/ } \\
\text { homogenate }\end{array}$ \\
\hline Human & $8.61 \pm 0.442(125)$ & $0.362 \pm 0.130(92)$ & $2.24 \pm 0.072(53)$ & $3.86 \pm 0.253$ \\
Rat§ & $13.00 \pm 0.764(53)$ & $0.805 \pm 0.047(53)$ & $0.48 \pm 0.002(55)$ & $21.1 \pm 1.68$ \\
Human/rat & $0.645 \pm 0.049$ & $0.455 \pm 0.027$ & $4.67 \pm 0.195$ & \\
\hline
\end{tabular}

Mean \pm SE

${ }^{*} \mu$ moles acetylcholine hydrolyzed/mg nitrogen per $30 \mathrm{~min}$.

$\ddagger$ Nanomoles acetylcholine hydrolyzed/end plate per $30 \mathrm{~min}$.

$\S$ From Namba and Grob (1).

These results were substantiated by histochemical studies. Slight overstaining for cholinesterase activity of human skeletal muscle resulted in precipitation of reaction products in the entire muscle (Figs. $2 a$ and $b$ ), whereas simultaneous staining of rat skeletal muscle produced reaction products only in the end plate area (Figs. $2 c$ and $d$ ).

From the number of motor end plates in human skeletal muscle membrane, a single motor end plate was calculated to have hydrolyzed 0.362 nmoles of acetylcholine
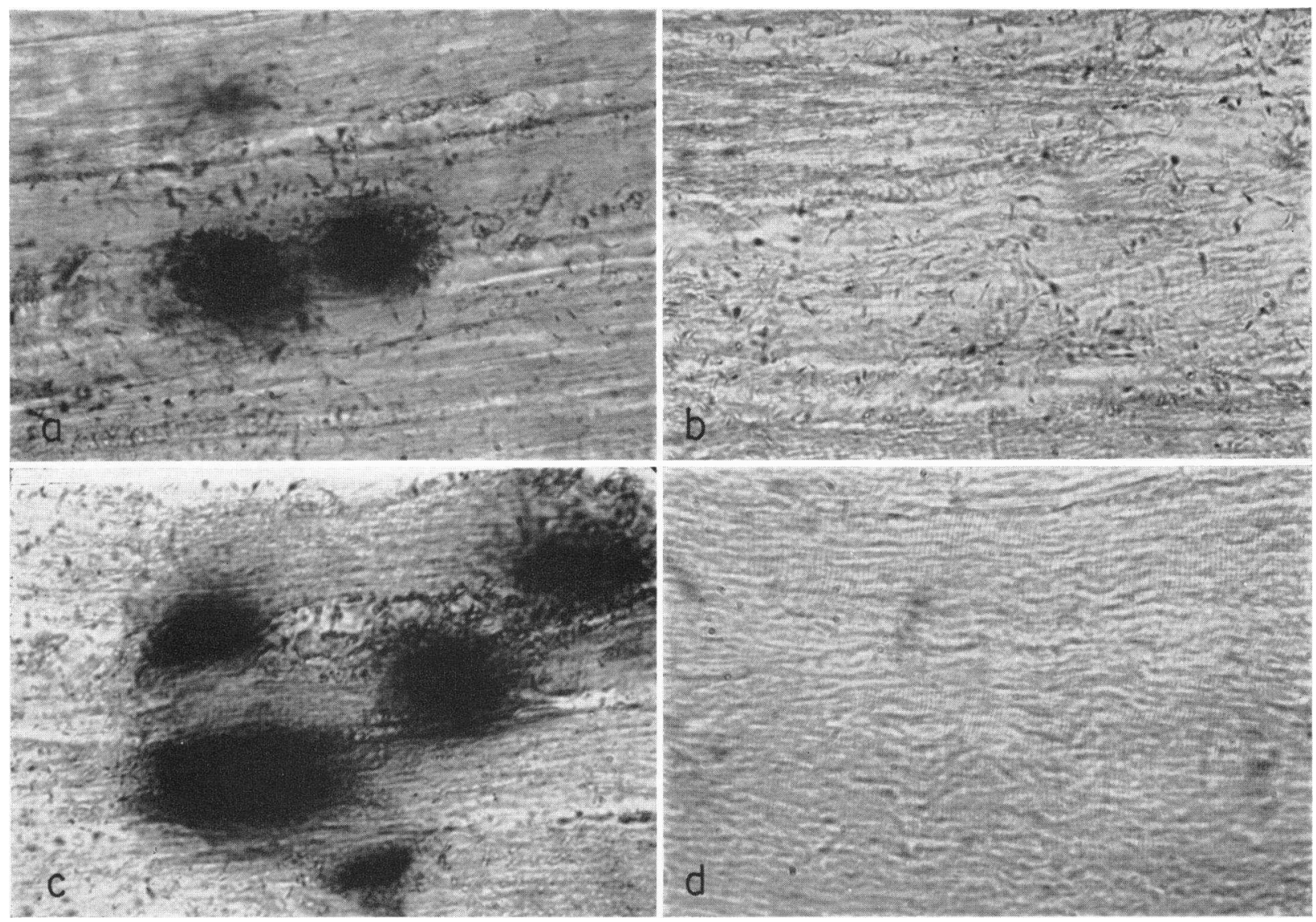

FigURE 2 Sections of intercostal muscle overstained for cholinesterase by incubation at $37^{\circ} \mathrm{C}$ for $20 \mathrm{~min}$. In human muscle, overstaining of motor end plates $(a)$ is accompanied by precipitation of the reaction products in the non-end plate area $(b)$. In rat muscle, motor end plates were greatly overstained $(c)$ but there was no reaction product in the non-end plate area $(d)$. Frozen sections, cholinesterase staining. $\times 465$. 


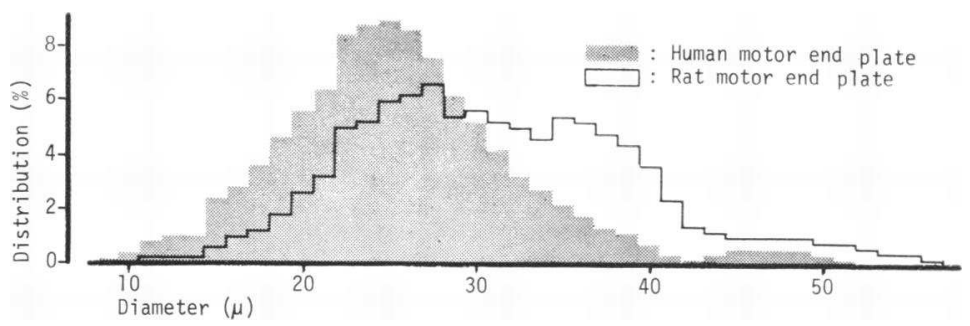

Figure 3 Diameter of motor end plates in the isolated membrane of human and rat intercostal muscles.

in $30 \mathrm{~min}$, or $1.21 \times 10^{8}$ molecules of acetylcholine per msec.

The mean cholinesterase activity of the human motor end plate was $45.5 \%$ of the mean activity of the rat motor end plate $(P<0.001)$ (Table I). However, individual estimations indicated considerable overlap in activities since the $95 \%$ tolerance limits of acetylcholine hydrolyzed in $30 \mathrm{~min}$ were $0.362 \pm 0.252$ nmoles in the human motor end plate and $0.805 \pm 0.689$ nmoles in the rat motor end plate. The diameter in the largest dimension was $25.94 \pm 0.317 \mu$ in the human motor end plate compared with $31.25 \pm 0.363 \mu$ in the rat motor end plate (mean $\pm \mathrm{SE}$ in 500 motor end plates, respectively, Fig. 3). Assuming that the shape of motor end plates is similar, the area of human motor end plate was 68.3 $\pm 2.86 \%$ (mean $\pm \mathrm{SE}$ in 500 end plates) of the area of rat motor end plate. Actually the synaptic area of human motor end plate consists of isolated sole plates whereas rat motor end plate is made up of a continuous sole plate. Therefore, cholinesterase activity per unit synaptic area appears to be in the same range in both human and rat end plates.

Properties of cholinesterase activity of human skelctal muscle membrane. There was no change in cholinesterase activity during storage of the suspension of skeletal muscle membrane at $4^{\circ} \mathrm{C}$ for $4 \mathrm{wk}$. The activity in 24 samples was $6.41 \pm 0.734$ initially and $6.65 \pm 0.847$ at 4 wk (mean $\pm \mathrm{SE}$, $\mu$ moles acetylcholine hydrolyzed in 30 min per $\mathrm{mg}$ of nitrogen).

Diisopropyl fluorophosphate (DFP) inhibited cholinesterase activity of the muscle membrane only slightly, while 1,5-bis-(4-trimethylammoniumphenyl)-n-pentane3-one (62C47) and 1,5-d-(4-alyl-dimethylammoniumphenyl)-pentane-3-one (284C51) greatly inhibited the enzyme activity (Table II). DFP is an inhibitor of pseudocholinesterase, inhib.ting less than $5 \%$ of acetylcholinesterase at $10^{-\tau} \mathrm{mole} / \mathrm{liter}$, and $100 \%$ of pseudocholinesterase at $10^{-8}$ mole/liter or higher concentrations (5) ; $62 \mathrm{C} 47$, an acetylcholinesterase inhibitor, inhibits $50 \%$ of acetylcholinesterase at $10^{-7.2} \mathrm{~mole} / \mathrm{liter}$ and $50 \%$ of pseudocholinesterase at $10^{-2.45}$ mole/liter (6); and 284C51, also an inhibitor of acetylcholinesterase, inhibits more than $95 \%$ of acetylcholinesterase and less than $5 \%$ of pseudocholinesterase at concentrations between $10^{-8}$ and $10^{-5}$ mole/liter (7). The muscle membrane hydrolyzed only $0.42 \pm 0.053 \mu$ moles (mean \pm SE in 59 measurements) of butyrylcholine per $\mathrm{mg}$ of nitrogen in 30 min. Butyrylcholine is a substrate for pseudocholinesterase. Cholinesterase activity of human skeletal muscle membrane therefore consists of more than $90 \%$ acetylcholinesterase and less than $10 \%$ pseudocholinesterase.

The amount of acetylcholine hydrolyzed by skeletal muscle membrane increased with increasing concentration of acetylcholine (substrate) between $0.5 \mathrm{mmole} /$ liter and 8.0 mmoles/liter (Fig. 4). When the results were plotted by the method of Woolf (8), a MichaelisMenten constant of 4.15 mmoles/liter and a maximum velocity of $15.8 \mu$ moles of acetylcholine hydrolyzed per $\mathrm{mg}$ of nitrogen in $30 \mathrm{~min}$ were obtained. Using the number of motor end plates counted in individual membrane preparations used in the study in Fig. 4, we calculated the maximum velocity of cholinesterase per motor end plate to be 0.754 nmoles acetylcholine hydrolyzed in $30 \mathrm{~min}$, or $2.52 \times 10^{8}$ molecules of acetylcholine hydrolyzed in $1 \mathrm{msec}$.

The optimal $\mathrm{pH}$ of the incubation medium for cholinesterase activity of human skeletal muscle membrane was 7.8 (Fig. 5).

TABLE II

Effect of Inhibitors on Cholinesterase Activity of Human Intercostal Muscle Membrane

\begin{tabular}{lrrr}
\hline \multicolumn{2}{c}{ Inhibitor } & $\begin{array}{c}\text { Cholinesterase } \\
\text { activity* }\end{array}$ & $\begin{array}{c}\text { Per cent } \\
\text { inhibition }\end{array}$ \\
\hline None & & $13.71 \pm 1.924$ & 0 \\
DFP & $10^{-7} \mathrm{M}$ & $13.12 \pm 1.826$ & 4.3 \\
& $10^{-6} \mathrm{M}$ & $11.00 \pm 1.098$ & 19.7 \\
$62 \mathrm{C} 47$ & $10^{-6} \mathrm{M}$ & $2.80 \pm 0.337$ & 79.5 \\
& $10^{-5} \mathrm{M}$ & $1.14 \pm 0.329$ & 91.6 \\
$284 \mathrm{C} 51$ & $10^{-6} \mathrm{M}$ & $1.45 \pm 0.357$ & 89.4 \\
& $10^{-5} \mathrm{M}$ & $1.34 \pm 0.836$ & 90.1 \\
\hline
\end{tabular}

* Mean $\pm \mathrm{SE}$ in 10 samples. $\mu$ moles of acetylcholine hydrolyzed/mg nitrogen per $30 \mathrm{~min}$. 


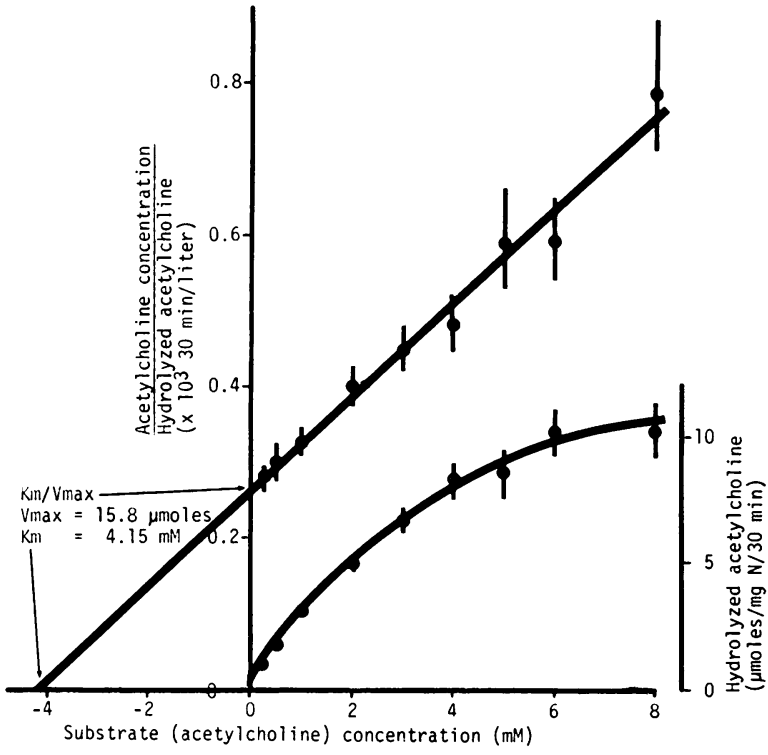

FIGURE 4 Effect of substrate concentration on cholinesterase activity of the isolated human skeletal muscle membrane. The circles indicate the mean, and the vertical lines the standard error of the mean, in 27 estimations.

\section{DISCUSSION}

Several studies have been reported on measurement of cholinesterase activity of motor end plates of experimental animals (Table III). In all but our previous study on the motor end plate of rat intercostal muscle (1), measurements were made on muscle segments which contained cholinesterase of both motor end plates and non-end plate components. Correction for cholinesterase of non-end plate components was made only by

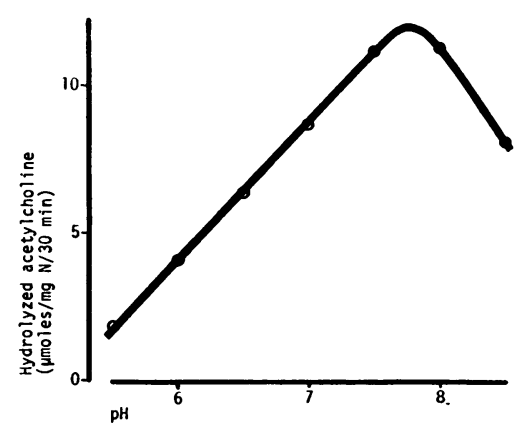

Figure 5 Effect of $\mathrm{pH}$ on cholinesterase activity of the isolated human muscle membrane.

Buckley and Nowell (10) and Buckley and Heaton (11), but their method was later found to have yielded low activity (15).

In the indirect measurement, the difference of cholinesterase activity between the muscle segments containing motor end plates and the segments without motor end plates is considered to be the cholinesterase activity of motor end plates. This method cannot be employed in human skeletal muscle, because the high cholinesterase activity of the segment without motor end plates renders the difference small and within the experimental error. Only about $2 \%$ of the cholinesterase activity of human intercostal muscle was estimated to be in the motor end plates, compared with $20 \%$ in rat tibialis anterior muscle (1).

Direct measurements of cholinesterase activity of motor end plates in human skeletal muscle have been found to be inaccurate, for the same reason, when carried out in muscle segments containing cholinesterase-

TABLE III

Cholinesterase Activity of Motor End Plate

\begin{tabular}{|c|c|c|c|c|}
\hline $\begin{array}{l}\text { Cholinesterase } \\
\text { activity* }\end{array}$ & Muscle & Substrate & Method & Reference \\
\hline $1.21 \times 10^{8}$ & Human intercostal & Acetylcholine & Direct & Present study \\
\hline $2.69 \times 10^{8}$ & Rat intercostal & Acetylcholine & Direct & (1) \\
\hline $1.45 \times 10^{7}$ & Rat tibialis anterior & Acetylcholine & Indirect & (1) \\
\hline $3.52 \times 10^{7}$ & Rat rectus abdominus & Acetylcholine & Direct & (9) \\
\hline \multirow[t]{2}{*}{$1.79 \times 10^{7}$} & Rat diaphragm & Acetylthiocholine & Direct & (10) \\
\hline & Rat extraocular muscle & Acetylthiocholine & Direct & (11) \\
\hline $0.35-6.46 \times 10^{7}$ & Focal end plate & & & \\
\hline $0.09-0.59 \times 10^{7}$ & Fine end plate & & & \\
\hline & Guinea pig extraocular muscle & Acetylthiocholine & Direct & (11) \\
\hline $0.54-7.31 \times 10^{7}$ & Focal end plate & & & \\
\hline $0.11-2.84 \times 10^{7}$ & Fine end plate & & & \\
\hline $3.70 \times 10^{8}$ & Rabbit gastrocnemius & Acetylcholine & Direct & (12) \\
\hline $2.90 \times 10^{7}$ & Mouse diaphragm & Acetylcholine & Direct & (13) \\
\hline $5.99 \times 10^{7}$ & Mouse gastrocnemius & Acetylcholine & Direct & (13) \\
\hline $1.6 \times 10^{9}$ & Frog sartorius & Acetylcholine & Indirect & (14) \\
\hline
\end{tabular}

* Molecules of substrate hydrolyzed per millisecond per end plate. 
active non-end plate components. The isolated muscle membrane is much more suitable for studies on the activity and properties of cholinesterase activity in motor end plates.

The function of non-end plate cholinesterase, which is localized mainly in the sarcoplasmic reticulum (16), is not known, but, from the comparative studies in muscle from man and from the rat, probably plays a very minor role, if any, in neuromuscular transmission. Motor end plates of humans appear to be more sensitive to acetylcholine than end plates of rats. In order to reduce the amplitude of muscle action potentials evoked by supramaximal nerve stimulation by $50 \%$, only about $2.5 \mathrm{mg}$ of acetylcholine was required when injected into the brachial artery of humans which supplies tissue weighing about $1000 \mathrm{~g}(17,18)$, whereas approximately $1.0 \mathrm{mg}$ of acetylcholine was required when injected into the common iliac artery of rats which supplies less than $10 \mathrm{~g}$ of tissue (19). Since the cholinesterase activity per unit synaptic area of end plate was approximately the same in man and rat, other factors may influence acetylcholine sensitivity.

Using cholinesterase activity of human motor end plate of $1.21 \times 10^{8}$ (acetylcholine molecules hydrolyzed per millisecond per motor end plate), we are able to make some quantitative estimations of the metabolism of acetylcholine at the end plate, although this value and other values obtained from the literature are obtained in experiments in vitro and may deviate from the actual values in vivo.

In human intercostal muscle, $4.04 \times 10^{10}$ molecules of acetylcholine have been reported to be stored in each motor end plate (20), and a mean of 218,000 quanta of acetylcholine has been reported to be releasable (21). If all the acetylcholine molecules stored in the motor end plate are releasable, the entire acetylcholine store would be hydrolyzed in $335 \mathrm{msec}$, and 650 quanta of acetylcholine can be hydrolyzed in $1 \mathrm{msec}$. Actually the releasable acetylcholine is only a fraction of the total acetylcholine store, and therefore acetylcholine greater than 650 quanta can be hydrolyzed in $1 \mathrm{msec}$.

The number of cholinesterase active sites in a motor end plate has been measured only in mice (Table IV). If one utilizes these numbers for the motor end plate of human intercostal muscle, the number of acetylcholine molecules hydrolyzed by one active site per minute (turnover number) ranges from $2.07 \times 10^{5}$ to $18.3 \times$ $10^{5}$ molecules, and the time required for one enzyme site to hydrolyze one acetylcholine molecule (turnover time) is 33-289 $\mu$ sec.

The number of acetylcholine molecules released from the nerve ending of a motor end plate per impulse has not been reported in humans. In experimental animals,
TABLE IV

Number of Cholinesterase-Active Sites, Acetylcholine Released per Impulse, and Acetylcholine Required for Stimulation, Per End Plate

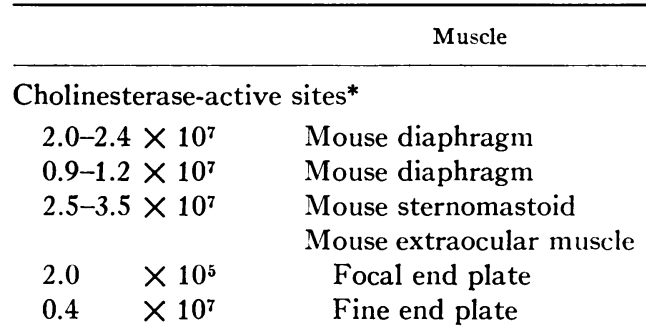

Reference

Acetylcholine recovered $\ddagger$

$\begin{array}{lll}4.64 & \times 10^{5} & \text { Mouse diaphragm } \\ 1.2 & \times 10^{5} & \text { Cat tibialis anterior } \\ 1.44 & \times 10^{6} & \text { Guinea pig diaphragm } \\ 6.64 & \times 10^{6} & \text { Rat diaphragm }\end{array}$

Acetylcholine required $\ddagger$

$\begin{array}{lll}3.3 & \times 10^{8} & \text { Frog } \\ 6.0 & \times 10^{8} & \text { Frog sartorius } \\ 9.05 & \times 10^{6} & \text { Rat diaphragm }\end{array}$

* Sites per end plate, measured by the number of bound IPF molecules.

$\ddagger$ Molecules of acetylcholine per impulse per end plate.

assessment of this number has been made by measuring acetylcholine recovered from muscle after stimulation of the motor nerve, and by determining the number of acetylcholine molecules required to stimulate a motor end plate when applied by micropipette (Table IV). These studies indicate that about $10^{7}$ molecules of acetylcholine per impulse are released from a motor end plate in experimental animals. If one utilizes this number for human intercostal muscle, the time required to hydrolyze acetylcholine which is released by one impulse is $83 \mu \mathrm{sec}$.

The number of possible acetylcholine receptor sites in an end plate was reported to be $4 \times 10^{\circ}$ in mouse diaphragm as measured by binding of curare compounds (22).

\section{ACKNOWLEDGMENTS}

The authors are grateful for assistance in biochemical, histochemical, and statistical analyses rendered by Mr. Panton H. Ebanks, Mr. Nathaniel H. Silverberg, and Miss Diane R. Kline, respectively. Dr. Abraham R. Kantrowitz and his staff gave kind cooperation during this study. Compounds $62 \mathrm{C} 47$ and $284 \mathrm{C} 51$ were provided by Dr. W. P. Colvin, Burroughs Wellcome \& Co.

This study was supported by U. S. Public Health Service Grant NB03464 from the National Institute of Neurological Diseases and Stroke, National Institutes of Health. 


\section{REFERENCES}

1. Namba, T., and D. Grob. 1968. Cholinesterase activity of the motor endplate in isolated muscle membrane. J. Neurochem. 15: 1445.

2. Hestrin, S. 1949. The reaction of acetylcholine and other carboxylic acid derivatives with hydroxylamine, and its analytical application. J. Biol. Chem. 180: 249.

3. Namba, T., T. Nakamura, and D. Grob. 1967. Staining for nerve fiber and cholinesterase activity in fresh frozen sections. Amer. J. Clin. Pathol. 47: 74.

4. Goldstein, A. 1964. Biostatistics. The Macmillan Company, New York.

5. Hawkins, R. D., and B. Mendel. 1947. Selective inhibition of pseudo-cholinesterase by diisopropyl fluorophosphonate. Brit. J. Pharmacol. 2: 173.

6. Todrick, A. 1954. The inhibition of cholinesterase by antagonists of acetylcholine and histamine. Brit. $J$. Pharmacol. 9: 76.

7. Austin, L., and W. K. Berry. 1953. Two selective inhibitors of cholinesterase. Biochem. J. 54: 695.

8. Christensen, H. N., and G. A. Palmer. 1967. Enzyme Kinetics. W. B. Saunders Company, Philadelphia.

9. Giacobini, E., and B. Holmstedt. 1960. Cholinesterase in muscles: a histochemical and microgasometric study. Acta Pharmacol. Toxicol. $17: 94$.

10. Buckley, G. A., and P. T. Nowell. 1966. Micro-colorimetric determination of cholinesterase activity of motor end plates in the rat diaphragm. J. Pharmacol. 18 (suppl.) : 146S.

11. Buckley, G. A., and J. Heaton. 1968. A quantitative study of cholinesterase in myoneural junctions from rat and guinea-pig extraocular muscles. J. Physiol. (London). 199: 743 .

12. Brzin, M., and $\check{z}$. Majcen-Tkačev. 1963. Cholinesterase in denervated end plates and muscle fibers. J. Cell. Biol. 19: 349 .

13. Brzin, M., and J. Zajicek. 1958. Quantitative determination of cholinesterase activity in individual end-plates of normal and denervated gastrocnemius muscle. Naturc (London). $181: 626$.

14. Marney, A., and D. Nachmansolnn. 1938. Cholin esterase in voluntary muscle. J. Physiol. (London). 92: 37.

15. Buckley, G. A., and J. Heaton. 1969. Decrease in cholinesterase activity of single motor end-plates after thiocholine staining. Brit. J. Pharmacol. 35:370P.

16. Namba, T., and D. Grob. 1967. Cholinergic receptors in skeletal muscle: isolation and properties of muscle ribo- nucleoprotein with affinity for $d$-tubocurarine and acetylcholine, and binding activity of the subneural apparatus of motor end plates with divalent metal ions. $A n n$. N. Y. Acad. Sci. 144: 772

17. Grob, D., R. J. Johns, and A. M. Harvey. 1956. Studies in neuromuscular function. III. Stimulating and depressant effects of acetylcholine and choline in normal subjects. Bull. Johns Hopkins Hosp. 99: 136.

18. Namba, T., and D. Grob. 1969. Effect of serum and serum globulin of patients with myasthenia gravis on neuromuscular transmission. Neurology. 19: 173 .

19. Namba, T., and D. Grob. 1969. Effect of antibodies against skeletal muscle constituents on muscle function in rats. Rev. Can. Biol. 28: 9.

20. Bianchi, C., L. Beani, and A. Bolleti. 1966. The acetylcholine content and choline-acetyl-transferase activity in human skeletal muscle. Experientia. 22: 596.

21. Elmqvist, D., W. W. Hofmann, J. Kugelberg, and D. M. J. Quastel. 1964. An electrophysiological investigation of neuromuscular transmission in myasthenia gravis. J. Physiol. (London). 174: 417.

22. Waser, P. G. 1967. Receptor localization by autoradiographic techniques. Ann. N. Y. Acad. Sci. 144: 737.

23. Barnard, E. A., and A. W. Rogers. 1967. Determination of the number, distribution, and some in situ properties of cholinesterase molecules in the motor end plate, using labeled inhibitor methods. Ann. N. Y. Acad. Sci. 144: 584.

24. Acheson, G. H. 1948. Physiology of neuro-muscular junctions: chemical aspects. Fed. Proc. $7: 447$.

25. MacIntosh, F. C. 1959. Formation, storage and release of acetylcholine at nerve endings. Can. J. Biochem. 37: 343.

26. Straughan, D. W. 1960. The release of acetylcholine from mammalian motor nerve endings. Brit. J. Pharmacol. 15: 417.

27. Krnjevic, K., and J. F. Mitchell. 1960. Release of acetylcholine in rat diaphragm. Nature (London). 186: 241.

28. Nastuk, W. L. 1953. Membrane potential changes at a single muscle endplate produced by transitory application of acetylcholine with an electrically controlled microjet. Fed. Proc. 12: 102.

29. Del Castillo, J., and B. Katz. 1955. On the localization of acetylcholine receptors. J. Physiol. (London). 128: 157.

30. Krnjevic, K., and R. Miledi. 1958. Acetylcholine in mammalian neuromuscular transmission. Nature (London). 182: 805 . 